\title{
Seeking Factors to Increase the Public's Acceptability of Road-Pricing Schemes Case Study of Spain
}

\author{
Paola Carolina Bueno, Juan Gomez, and Jose Manuel Vassallo
}

\begin{abstract}
User acceptability has become a critical issue for the successful implementation of transport pricing measures and policies. Although several studies have addressed the public acceptability of road pricing, little evidence can be found of the effects of pricing strategies. The acceptability of alternative schemes for a toll network already in operation is an issue to be tackled. This paper contributes to the limited literature in this field by exploring perceptions toward road-pricing schemes among toll road users. On the basis of a nationwide survey of toll road users in Spain, the study developed several binomial logit models to analyze user acceptability of three approaches: express toll lanes, a time-based pricing approach, and a flat fee (vignette) system. The results show notable differences in user acceptability by the type of charging scheme proposed. Express toll lanes were more acceptable by travelers who perceived greater benefits from saving travel time. The acceptability of time-based approaches (peak versus off-peak) decreased for users who felt forced to use the toll road, whereas this was not an aspect that significantly influenced users' support for flat fee schemes. In addition, a flat fee strategy was more acceptable for long-distance trips and truck drivers who regularly used the toll facilities. The results from this analysis can inform policy makers and planners for the promotion of more efficient, socially inclusive, and publicly acceptable road-pricing schemes.
\end{abstract}

Road charging remains one of the most debated topics for transportation planners and researchers. Given that road charging encourages users to pay for the external costs they produce, it has been a transportation policy advocated by economists for decades. In practice, the implementation of road-pricing mechanisms has proven to be an effective instrument in achieving the objectives of congestion relief, environmental improvements, and revenue generation in the face of public budget constraints.

Congestion-charging schemes have been implemented in urban environments, such as Singapore (1975), Oslo (1990), London (2003), and Stockholm (2006), among others. Pricing schemes have been implemented in metropolitan and interurban contexts worldwide, under the approach of toll road concessions, generally managed by private operators, or, especially for European countries, tolling schemes adopted by national authorities as a funding source and a way to promote efficient road mobility in interurban contexts.
One of the major obstacles to the widespread implementation of road charging is its still scarce public acceptability (1). Previous research has clearly shown that public acceptability of such measures is low, with considerable public resistance to road pricing in Europe and beyond, as was evidenced by Link and Polak (2). Nevertheless, public opposition to charging policies is not inevitable, as was pointed out by Jaensirisak et al. (3). For instance, spending road revenues on public transport or setting an understandable and reasonable pricing purpose may contribute to minimizing opposition to road charges and increasing their political acceptability.

Acceptability of road-pricing schemes is determined by several factors, which can be broadly classified into three main categories. The first group comprises socioeconomic characteristics, such as income, age, gender, and labor status, among others. The second category includes some trip-related attributes, such as trip purpose or frequency. The third group covers attitudinal factors specific to individuals, including perceptions and beliefs about road pricing, as well as context-specific variables.

In the extensive literature on road-pricing acceptability, some important issues have not yet received the attention they deserve. A key issue is the extent to which the type of pricing scheme applied may influence user acceptability toward tolling. The current evidence on the relationship between acceptance and various charge schemes is inconclusive and has not been analyzed in detail $(3,4)$.

This study aimed to gain insight into how toll road user acceptability might be improved, and establish some policy recommendations for implementing more effective pricing policies. The study explored differences in user acceptability of alternative charging systems to be potentially implemented: a surcharge to avoid congestion at any time (express toll lanes), a time-based (peak versus off-peak) pricing approach, and a flat fee (vignette) system. The results of this study are also useful for identifying user market segments, as well as targeting effective messages to specific groups at the time of the implementation of the proposed pricing systems.

The study analyzed users' perceptions through stated-preference choices from real users of the toll network, as was done by Gomez et al. (5) for Spain, and Odeck and Bråthen (6) for Norway. However, as far as the authors are aware, this methodology has not been used to model the acceptability of alternative pricing strategies. The analysis was carried out based on a nationwide survey of users of the toll motorway network in Spain. As other authors have done $(7,8)$, the information was obtained from drivers who use the toll road mainly for work purposes (commuting and work trips paid by the user). This group was selected because it is more captive of the road than leisure drivers are.

This paper provides a literature review on the topic and briefly describes the case study analyzed: the toll road network in Spain. 
It then outlines the methodology adopted for the research, and presents the survey and explanatory variables that were considered for the analysis. Finally, the paper discusses the results and provides conclusions and policy recommendations.

\section{LITERATURE REVIEW}

\section{Acceptability of Road Pricing}

Many books and academic papers have examined attitudes toward road-pricing strategies [e.g., Jakobsson et al. (9); Noordegraaf et al. (10)]. Among previous studies exploring the phenomenon of public acceptance, it was commonly agreed that gaining support for road pricing constitutes one of the main policy objectives toward a broader implementation of these schemes, as was found by Jakobsson et al. (9) and Schade and Baum (11).

Acceptability of road charging has been formally evaluated in different ways. These include, among others, full-scale trials, as developed in Stockholm, and referendums, as in the case of Edinburgh or Sidney. Studies of the acceptability of road pricing have covered many contexts. These studies include real cases such as Stockholm and Milan and hypothetical implementations such as London and Leeds in the United Kingdom, and New York and Virginia in the United States. As noted by Grisolía et al. (12), the recent literature has shown growing interest in the issue of acceptability by the general public and politicians, generally aimed at extracting lessons from previous charging implementations [e.g., Odeck and Bråthen (6); Noordegraaf et al. (10)]. Furthermore, many contributions have focused on public opinion toward the concept of pricing, as in Li and Hensher (13) and Fürst and Dieplinger (14).

The following list presents the main conclusions that can be drawn from a detailed review of previous contributions dealing with attitudes toward road pricing, to identify the gap in the literature that motivated this research.

- Most of the previous studies acknowledged that public support for transport pricing measures and policies is often quite low (15), with citizens generally opposed to this type of measure [e.g., Harsman et al. (16)].

- Acceptability is not predetermined and may be influenced by, and hence can be changed through, a variety of attitudinal, empirical, and political persuasions (17). The literature has shown that pricing is more acceptable $(a)$ if the purpose and benefits of the policy are clearly understood; $(b)$ if the objectives of the scheme address public concerns, such as environmental issues; and $(c)$ if revenues are spent in the transport sector [e.g., Odeck and Bråthen (6); Gaunt et al. (15)]. Some policies, such as reasonable allocation of revenues or appropriate compensation to the losers, are expected to increase the perceived sentiment of fairness.

- The type of pricing scheme may influence the level of acceptability. However, the current evidence on the relationship between public acceptance and various charging schemes is not conclusive. As acknowledged by May et al. (4), some authors have found little difference between the acceptability of cordon, distance, and delaybased charges (18), while other analyses have demonstrated that there are large differences in acceptability, depending on the characteristics of the charging system (19). In general, previous research has shown that more complex schemes are likely to be less acceptable $(20,21)$. All the research studies mentioned have explored public acceptability of the hypothetical implementation of different types of road-pricing schemes. By contrast, there is a need to analyze the effects of public acceptability based on the point of view of those individuals who are already charged for using roads.

- Several factors may influence the acceptability of road pricing. In general, these factors can be grouped into sociodemographic characteristics, trip-related attributes, attitudinal variables, and other factors such as attributes of the pricing scheme. For example, some studies have found that car drivers show lower acceptability compared with public transport users (22), while other authors have identified the region of residence as one of the most significant determinants of the acceptability of road pricing (20). Furthermore, some contributions have pointed out that socioeconomic factors may have a somewhat lesser impact on acceptability than attitudinal factors have $(3,18,23)$.

- Current evidence of the influence of socioeconomic or transportrelated factors (age, income, trip purpose, and so forth) on perceptions toward road pricing was not conclusive at the time of this study. For instance, some empirical studies have found a positive relationship between age and acceptance (23), while others have found no significant relationship (24) or even a negative correlation (3). Some authors have found that women support road pricing more strongly than men do (24), while the opposite occurs in the case of Edinburgh (25). Gehlert et al. (26) also provided examples of socioeconomic differences in public acceptability of road pricing.

- Analysis of the social impacts and equity implications has focused on the additional burdens of road-pricing measures. Some studies have suggested that the higher is the level of income, the less important is the additional burden from road-pricing charges (27). However, some other research has not confirmed the relationship between the support for pricing options and the level of income (19), or interpreted road charging as a regressive policy in income distribution (7).

- The literature review showed a significant body of research on public acceptability. However, there are still many points to be addressed. First, the fundamental issue of the influence of different road-pricing schemes on acceptability has not received great attention in the academic literature, as was recognized by Jaensirisak et al. (3). There is a need to explore how the adoption of a different charging scheme may contribute to changing user acceptability for road facilities that are already tolled. Second, previous research mainly focused on urban areas, showing particular interest in the implementation of congestion-charging systems $(28,29)$, while large-scale acceptability studies that focused on interurban roads were particularly limited (30). Finally, there has been no consensus in the literature on the influence of personal characteristics and attitudinal factors on user acceptability, which is essential to provide good guidance for policy makers.

\section{Spain's Toll Road Network}

In the early 1970s, tolls were introduced in Spain with the objective of developing high-quality road projects in a period of scarce budgetary resources (31). Spain's high-capacity network has a total of $16,583 \mathrm{~km}$, one of the longest in Europe. The network is made up of toll and free high-capacity roads. The toll road concessions represent $18.2 \%$ of the high-capacity network currently in operation (32). A detailed description of the evolution of Spain's toll road network was beyond the scope of this study. Interested readers are referred to Gomez et al. (5). However, to understand the context of the stated preference survey, it is necessary to give some information about the toll road system in Spain. 
Spain's national toll road network is made up of two types of tolled infrastructure: tunnels, representing only around $1 \%$, and interurban road stretches of tolled motorways, the vast majority of the toll network (99\%). Toll rates are established depending on the distance traveled, according to a euro/ $\mathrm{km}$ rate regulated by the contract for each concession. Nevertheless, a wide range of variation of rates is found throughout the network. Current toll rates for light vehicles fall in the range of 0.07 to 0.10 euro $/ \mathrm{km}$. By contrast, a fixed toll is charged for crossing tunnels. In unitary values, toll rates for light vehicles in this type of infrastructure are quite expensive, from 0.143 euro $/ \mathrm{km}$ (Eje Aeropuerto tunnel) to 0.49 euro $/ \mathrm{km}$ (Artxanda tunnels). Furthermore, tolls vary across vehicle types, with toll rates applied to heavy vehicles being around 50\% higher than those for light vehicles.

The rate per kilometer usually does not vary by the hour of the day or seasonally. Only some toll roads apply a somewhat flexible toll scheme, according to which different charges are paid at peak and off-peak times. This is the case of certain toll roads in the region of Madrid (Radials 2, 3, 4, and 5), one bypass in the region of Valencia (Circunvalación de Alicante), and one tunnel in Catalonia (Túnel de Vallvidrera). Toll operators for these roads offer discounts during off-peak hours, ranging between $50 \%$ and $90 \%$ for light and heavy vehicles. By contrast, most of the toll motorways, around $63 \%$ of the toll network in operation, provide discounts for frequent users.

Given the historical evolution of the country's toll policy, the current network is asymmetrically distributed throughout the territory [Gomez et al. (5) provide more details]. Although a significant percentage of the high-capacity network is tolled in certain regions, other areas have free high-quality roads. In addition, toll roads in Spain always have a free parallel road available serving the same corridor. Generally, the alternative road is a conventional (two-lane) road, and therefore of lower quality. Nevertheless, some of the toll roads have a free high-capacity road competing with them, with similar physical and design characteristics, as in the region of Madrid.

\section{METHODOLOGY}

\section{Data Sources and Variables}

The study aimed to explore users' perceptions toward various roadpricing schemes, given that a toll network is already in operation. To that end, a nationwide survey was conducted in Spain's toll network, to collect users' perceptions toward the implementation of three hypothetical road-pricing schemes to be potentially implemented in the current toll network. This research focused on individuals who used the toll roads mainly for working purposes, since, to a large extent, this group of road users had fewer options to modify their travel behavior after a change in the pricing scheme has been implemented. Overall, 1,176 real users (frequent and occasional) reported their perceptions. According to Ben-Akiva (33), the sample size can be considered representative enough for a stated-preference survey.

The survey considered the following pricing schemes to explore respondents' perceptions:

- A surcharge to avoid congestion at any time (express toll lanes). Users were asked to indicate their general perception toward a scheme that gives everyone the option of paying a supplementary fee to access a separate free-flow travel lane, or remaining in the existing lanes. Although express toll lanes are dynamically priced facilities, the survey participants were asked about the case of paying a fixed surcharge, irrespective of demand. It was decided to ask about this simplified base case, since in Spain there has been no previous experience with variably priced managed lanes.

- Time-based (peak versus off-peak) pricing scheme. The survey asked the respondents their opinions about applying different toll rates (euro/km) within the same day or seasonally. With this system, all drivers pay higher charges during peak hours and lower rates during off-peak hours.

- Flat fee-charging (vignette) system. Finally, respondents were asked whether they were willing to pay a monthly flat fee, regardless of the mileage driven in the toll network and the period of time in which they use the toll road infrastructure. In this case, the people who were surveyed were told that the amount of the monthly flat fee would be similar to the amount they were currently paying for use of the road each month.

The responses to these schemes, grouped into two categories (positive and negative toward the change), made up the dependent variable of the binary choice models aimed at analyzing users' perceptions. In the end, three models were calibrated to explore attitudes toward the three schemes that were proposed.

The explanatory variables in the model comprise socioeconomic characteristics, trip-related attributes, and attitudinal variables (Table 1). The socioeconomic characteristics include gender, age, income, and region of residence. The latter variable was included because of its importance in explaining differences in users' attitudes and willingness to pay that were caused by the asymmetrical distribution of the toll network throughout Spain, as was pointed out by Gomez et al. (5). The second group of variables refers to personal trip-related attributes, such as the type of user (frequency), type of vehicle, and type of trip usually made (urban or metropolitan, long distance, and so forth). The third group of variables is comprised of attitudinal factors, including behavioral reactions and users' perceptions about the toll facility they currently use, such as its quality, effectiveness in helping them save time, and so forth. This group also captured whether drivers felt more or less captive to use the toll road, which may have been influenced by the alternative modes or routes available to each user.

Data collected from the survey were complemented with information related to the attributes of the existing toll facility. Within this group of variables, an explanatory factor was incorporated to control whether existing toll facilities already applied a time-based charge or established discounts for frequent users. Furthermore, given that toll highways in Spain always have a free alternative serving the same corridor, the study included the quality of the free parallel roadwhether it was a conventional (two-lane) or high-capacity road-and the quality of the toll road as potential explanatory factors to explain drivers' perceptions. Since the quality of the toll road was not directly measurable, it was decided to incorporate it as a latent variable in the modeling approach, as detailed in Table 1.

Because most of the explanatory variables were categorical, a base case (BC) was selected as a reference to identify potential differences in user acceptability (Table 1). For example, for age, the study chose younger than 24 years as the BC. This choice allowed the study to measure whether user acceptability in the other age categories was statistically significant compared with the reference case.

The sample had a balanced distribution of respondents across regions, with a higher presence of people ages 35 to 49 years (46.5\%). Income was typically between $€ 20,000$ and $€ 30,000$; the majority were frequent toll road users $(82.1 \%)$, and most were car drivers $(80.6 \%)$. Over half the respondents felt forced to use toll roads 
TABLE 1 Summary of Variables Included in the Study

\begin{tabular}{|c|c|c|c|}
\hline Variable & Category & Respondents & Sample $(\%)$ \\
\hline \multicolumn{4}{|l|}{ Dependent } \\
\hline \multicolumn{4}{|l|}{ Perceptions toward the implementation of } \\
\hline \multirow{3}{*}{$\begin{array}{l}\text { Model 1: Surcharge to avoid congestion } \\
\text { at any time (express toll lanes) }\end{array}$} & Accept & 641 & 54.5 \\
\hline & Reject & 532 & 45.2 \\
\hline & MV & 3 & 0.3 \\
\hline \multirow{3}{*}{$\begin{array}{l}\text { Model 2: Time-based (peak versus off-peak) } \\
\text { scheme }\end{array}$} & Accept & 257 & 21.9 \\
\hline & Reject & 917 & 78.0 \\
\hline & MV & 2 & 0.2 \\
\hline \multirow[t]{3}{*}{ Model 3: Flat-fee (vignette) system } & Accept & 640 & 54.4 \\
\hline & Reject & 535 & 45.5 \\
\hline & MV & 1 & 0.1 \\
\hline \multicolumn{4}{|l|}{ Explanatory } \\
\hline \multicolumn{4}{|l|}{ Socioeconomic characteristics } \\
\hline \multirow[t]{2}{*}{ Gender } & Male (BC) & 749 & 63.7 \\
\hline & Female & 427 & 36.3 \\
\hline \multirow{5}{*}{ Age } & Under 24 years $(B C)$ & 62 & 5.3 \\
\hline & $24-34$ years & 233 & 19.8 \\
\hline & $35-49$ years & 547 & 46.5 \\
\hline & $50-64$ years & 302 & 25.7 \\
\hline & Above 64 years & 32 & 2.7 \\
\hline \multirow[t]{5}{*}{ Income } & Under 20,000 euro (BC) & 237 & 20.2 \\
\hline & From 20,000 to 30,000 euro & 323 & 27.5 \\
\hline & From 30,000 to 50,000 euro & 165 & 14.0 \\
\hline & Above 50,000 euro & 50 & 4.3 \\
\hline & MV & 401 & 34.1 \\
\hline \multirow[t]{5}{*}{ Region } & Catalonia (BC) & 271 & 23.0 \\
\hline & Madrid & 229 & 19.5 \\
\hline & Valencia & 247 & 21.0 \\
\hline & Galicia & 196 & 16.7 \\
\hline & Basque Country & 233 & 19.8 \\
\hline \multicolumn{4}{|l|}{ Trip-related attributes } \\
\hline \multirow[t]{2}{*}{ Type of user } & Occasional (BC) & 210 & 17.9 \\
\hline & Frequent & 966 & 82.1 \\
\hline \multirow[t]{6}{*}{ Type of vehicle } & Car (BC) & 948 & 80.6 \\
\hline & Van & 121 & 10.3 \\
\hline & Truck & 94 & 8.0 \\
\hline & Motorcycle & 5 & 0.4 \\
\hline & Bus & 7 & 0.6 \\
\hline & Other & 1 & 0.1 \\
\hline \multirow[t]{3}{*}{ Type of trip } & Urban-metropolitan trip (BC) & 257 & 21.9 \\
\hline & Interurban trip & 594 & 50.5 \\
\hline & Long distance & 325 & 27.6 \\
\hline \multicolumn{4}{|l|}{ Attitudinal factors } \\
\hline Quality of the toll road facility ${ }^{a}$ & & Mean: -0.022 & SD: 1.03 \\
\hline \multirow[t]{2}{*}{ Forced to use the toll road $^{b}$} & Not forced (BC) & 457 & 38.9 \\
\hline & Forced & 719 & 61.1 \\
\hline \multirow[t]{4}{*}{ Qualitative willingness to pay ${ }^{c}$} & Low (BC) & 426 & 36.2 \\
\hline & Medium & 383 & 32.6 \\
\hline & High & 362 & 30.8 \\
\hline & MV & 5 & 0.4 \\
\hline \multirow[t]{3}{*}{ Perception of the cost of the toll road $^{d}$} & Cheap (BC) & 11 & 0.9 \\
\hline & Expensive & 997 & 84.8 \\
\hline & Reasonable & 168 & 14.3 \\
\hline Perception of the contribution of the & Positive (BC) & 961 & 81.7 \\
\hline toll road to save time $e^{e}$ & Negative & 34 & 2.9 \\
\hline & $\begin{array}{l}\text { Sometimes positive, } \\
\text { sometime negative }\end{array}$ & 181 & 15.4 \\
\hline
\end{tabular}


TABLE 1 (continued) Summary of Variables Included in the Study

\begin{tabular}{|c|c|c|c|}
\hline Variable & Category & Respondents & Sample (\%) \\
\hline \multicolumn{4}{|l|}{ Other } \\
\hline Existing time-based charge $\mathrm{e}^{f}$ & & Mean: $97 \%$ & SD: 10.2 \\
\hline \multirow{2}{*}{ Existing discount for frequent users ${ }^{g}$} & No (BC) & 649 & 55.2 \\
\hline & Yes & 527 & 44.8 \\
\hline \multirow[t]{2}{*}{ Quality of the free alternative road $^{h}$} & Conventional road $(\mathrm{BC})$ & 945 & 80.4 \\
\hline & Highway & 231 & 19.6 \\
\hline
\end{tabular}

Note: $\mathrm{MV}=$ missing values; $\mathrm{BC}=$ base case.

${ }^{a}$ The variable was treated as a latent variable. It comes from the users' perception of the speed, security, general quality, and available services of the toll road facility.

${ }^{b}$ This variable was derived from the following question: Are you forced, or have you been forced, to use toll roads?

${ }^{c}$ To build this variable, the survey asked respondents to choose between different hypothetical situations of qualitative willingness to pay (QWTP). A high QWTP means that the driver is willing to use toll roads by paying whatever is needed; a medium QWTP means that the user is willing to pay a certain amount of money; and a low QWTP means that the respondent is willing to pay a small amount of money.

${ }^{d}$ To build this variable, the survey asked the following question: Do you think the toll fees you pay are cheap, expensive, or reasonable?

${ }^{e}$ The car drivers were asked whether they perceived the toll facility as an effective means for saving travel time.

${ }^{f}$ This variable represents the percentage of the full fee (peak tariff) that users pay compared with off-peak usage. The value $100 \%$ means there is no existing time-based change scheme in this toll road (peak tariff $=$ off-peak tariff).

${ }^{8}$ This variable identifies which toll facilities currently provide discounts for frequent users or not.

${ }^{h}$ Depending on the toll road used, the study classified the free parallel road available in the corridor as a highway or a conventional road, assuming the quality to be high when the free parallel road happened to be a highway.

$(61.1 \%)$. This does not mean that toll road users had no other option, since toll highways in Spain always have a free alternative available, although it is of much lower quality in most cases. Finally, the majority of the respondents perceived that the current toll rates applied in the toll network were expensive. However, their attitude toward the effectiveness of toll roads in contributing to save travel time was mostly positive $(81.7 \%)$. Some variability was found in the other explanatory variables. Table 1 provides further information on the descriptive statistics of the explanatory variables included in the study.

\section{Binary Logit Models}

The study calibrated three binary logit models to determine the factors that influence commuters' acceptability of the three pricing schemes proposed. Binary choice models were derived from utilitymaximizing theory, according to which decision makers are utility maximizers. The individual chooses, among all the options available, the alternative measuring her or his utility, which can be determined by several explanatory variables. The study considered four types of parameters determining individuals' choices within the modeling approach: socioeconomic characteristics of the individual $(S)$, trip-related attributes $(T)$, attitudinal factors $(A)$, and other variables related to the road facility $(O)$. The utility $\left(U_{i k}\right)$ gained by individual $i$ from choosing alternative $k$ can be written as shown in Equation 1:

$U_{i k}=f\left(S_{i}, T_{i k}, A_{i k}, O_{i}\right)$

Recalling that $U_{i k}$ is considered a random variable, it can be divided into two additive parts (Equation 2):

$U_{i k}=\sum_{j} V_{i k}+\varepsilon_{i k}=\sum_{j} \beta_{j} X_{i k}+\varepsilon_{i k}=\lambda_{S} S_{i}+\gamma_{T} T_{i k}+\alpha_{A} A_{i k}+\mu_{O} O_{i}+\varepsilon_{i k}$ where

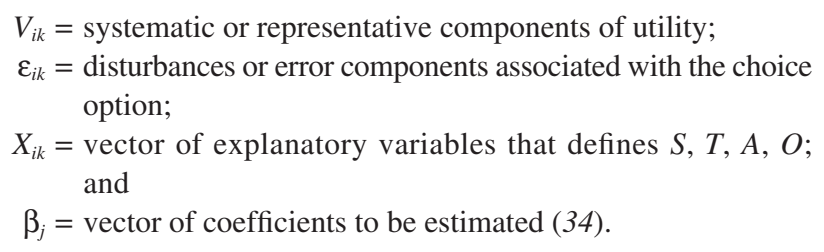

Economic theory assumes that individual $k$ will choose the option with the highest utility. As explained by Ben-Akiva (33), in the general form of a binary choice model, the probability that respondent $k$ will choose alternative $i, P_{i}$, can be expressed as follows:

$P_{i}=\frac{e^{V_{i k}}}{\sum_{j} e^{V_{i j}}}$

The binary logit approach predicts the so-called logit of the odds ratio, $L_{i}$, given multiple explanatory variables $X_{i}(35)$. The specification that the study finally adopted has the classical form of a binary logit model:

$L_{i}=\ln \frac{P_{i}}{1-P_{i}}=\alpha+\beta_{1} x_{1}+\beta_{2} x_{2}+\cdots+\beta_{k} x_{k}$

As a consequence of this linearization process, the interpretation of the $\beta_{k}$ coefficients is different from that of standard linear regression models. The slope coefficient suggests that for a unit increase in a certain explanatory variable $X_{k}$, the weighted log of the odds in favor of a certain alternative $(Y=1)$ increases by $\mathrm{e}^{\beta k}$. More appealingly, for a unitary increase in a certain explanatory variable $X_{k}$, the odds ratio in favor of $Y=1$ happening increases by $\mathrm{e}^{\beta k}$.

A more detailed description of binary choice models is beyond the scope of this paper. Further details are provided in Ben-Akiva (33) and Ortúzar and Willumsen (36). 


\section{RESULTS}

This section summarizes the main findings of the analysis conducted in this research. The study developed different discrete choice models to estimate the probability of supporting certain road-pricing schemes. The analysis modeled user acceptability toward changing the current pricing scheme of toll roads, in which a constant per kilometer toll was applied, for three hypothetical alternatives: a surcharge to avoid congestion at any time, an express toll lane (Model 1); a time-based peak versus off-peak scheme (Model 2); and a flat fee-charging (vignette) system (Model 3). Before the calibration process, tests were conducted aimed at identifying potential multicollinearity problems among the explanatory variables, and showed no significant interactions.

The final results of the modeling analysis are shown in Table 2. The table contains some effects that are not significant at the $95 \%$ confidence level ( $p$-value $>.05$ ), but were kept in the model since they were nearly significant in at least one of the three models estimated. The omitted variables, with no significant effects in all three models, are income and the categorical variable showing whether the existing toll roads already apply a time-based toll scheme (the existing time-based charge variable). The modeling results for these variables are not discussed since there is no statistically significant evidence of explanatory effects. As is commonly done for logit model analysis, the slope coefficients of the explanatory variables $\left(\beta_{k}\right)$ are evaluated according to a twofold criterion: $(a)$ the sign of the coefficient, and $(b)$ its magnitude.

The results of Model 1 provide evidence that acceptability toward the implementation of an express toll lane is significantly lower when the user perceives that the toll road is not that useful for saving travel time (coefficient -0.784 ). The model reflects that users do not want to pay more if charging is not an efficient solution for saving travel time. The support for the express lane-charging system also varies significantly across age and gender, keeping the rest of the variables constant. However, this scheme seems to be more acceptable to frequent users (coefficient 0.290 ), and is somewhat positively influenced by the quality of the toll road facility (coefficient 0.10 ). These findings are likely because people are more willing to pay more when the quality of the toll road is better. Finally, the acceptability of this approach is also influenced by regional factors. As was pointed out by Gomez et al. (37), regional differences in users' attitudes may be influenced by an asymmetrical distribution of toll infrastructure facilities across the regions in a country. For the case of Spain, the authors analyzed in detail the impact of regionalism on users' perceptions. This study found that users from Madrid are more willing to tolerate an express toll lane (coefficient 0.457 ), likely because they are more aware of congestion than people in other regions are. Consequently, a change in the current pricing scheme in Madrid was possibly not perceived as a burden, but a supplementary option that would potentially be useful when the free alternative becomes congested.

In line with the first model, the results for Model 2-exploring acceptability toward a time-based (peak versus off-peak) pricing scheme-reveal that socioeconomic characteristics influence users' perceptions toward this pricing strategy only to a minor extent. By contrast, transport-related attributes play a more important role in explaining user acceptability. The time-based system becomes less acceptable for individuals who feel forced to use the toll road, since this variable is found to be negatively related (coefficient -0.414) to the probability of supporting this charging scheme. This result may be explained by the fact that respondents who were not provided with a free quality alternative perceived charges at peak times as a potential additional burden, so they wanted to avoid an extra fee. The study also found a notable increase in the acceptability results if the toll road used by the respondent was of good quality (coefficient 0.145 ). Among the personal and socioeconomic attributes, no significant differences were found throughout the subgroups for region, type of user (trip frequency), age, type of vehicle, or type of trip. Furthermore, a significantly more negative attitude toward different charges at peak and off-peak times was observed in the case of females (coefficient -0.539 ). This finding is in line with previous results on gender referred to in the literature (25). However, there are no consistent conclusions concerning the influence of gender in the general acceptability of road pricing. Finally, it was surprising that past experiences with existing time-based strategies did not significantly influence users' attitudes. It may have been that the interpretation of what a time-based pricing scheme exactly implies varied widely across individuals.

The results from Model 3 reveal that attitudinal factors have a strong influence on users' perceptions toward a flat fee (vignette) scheme. As could be expected, perceiving the current toll to be expensive or reasonable might be strongly associated with support for this pricing strategy (coefficients 0.933 and 0.170 , respectively). Unlike the results obtained with the previous models, a flat fee system would be more acceptable for captive users (coefficient 0.183 ), that is, those who feel more obliged to use the toll network. These results indicate that a toll road pass may be interpreted by respondents as a possibility for driving higher mileage without an extra payment, so it seems to be perceived as a potential way to save money. Moreover, as has been pointed out in the literature, people prefer to know how much the charge will be before traveling (38). Further, other trip-related attributes can influence the acceptability of road pricing. Within this group of variables is the case of truck drivers, who are also frequent users of the toll road network. The results of this model show that truck drivers are $2.5\left(=e^{0.921}\right)$ times more likely to support a flat fee system than car users are, keeping the other variables constant (Table 2). Model 3 also finds that perceptions toward the vignette scheme become more positive as the length of the trip increases. Users who make long-distance trips are two $\left(=e^{0.701}\right)$ times more likely to support a flat tariff option compared with users who make short trips. Finally, the flat fee scheme was found to be more acceptable by individuals who use toll facilities without existing discounts, although a statistically significant influence cannot be concluded from this analysis $(p$-value $=.079)$. Overall, the acceptability of this approach becomes higher when users expect to save money with its implementation.

From the three cases studied, specific significant determinants of acceptability can be found for each pricing scheme. As generally found in the literature on the acceptability of road pricing, it can be claimed that attitudinal factors have greater explanatory power compared with socioeconomic variables. A statistically significant influence cannot be concluded from this analysis for the income variable. Differences between wealthy and poor drivers do not appear to explain the variability in their acceptability of road-pricing schemes. This result is in line with other papers found in the literature, such as Jaensirisak et al. (3) and Dill and Weinstein (19).

For the goodness of fit of the estimated results, the models obtained rho-squared values between .063 and .097 , which may be considered acceptable for logit specifications according to Hensher and Bradley (39). Furthermore, the signs of the regression coefficients and their statistical and practical significance are in line with the expected results. 


\begin{tabular}{|c|c|c|c|c|c|c|}
\hline \multirow[b]{2}{*}{ Variable } & \multicolumn{2}{|c|}{$\begin{array}{l}\text { Model 1: Express } \\
\text { Toll Lane }\end{array}$} & \multicolumn{2}{|c|}{ Model 2: Time Based } & \multicolumn{2}{|c|}{$\begin{array}{l}\text { Model 3: Flat Fee } \\
\text { (vignette) }\end{array}$} \\
\hline & Coefficient & $p$-Value & Coefficient & $p$-Value & Coefficient & $p$-Value \\
\hline \multicolumn{7}{|c|}{ Socioeconomic Characteristics } \\
\hline $\begin{array}{l}\text { Gender } \\
\text { Male (BC) } \\
\text { Female }\end{array}$ & -0.184 & .157 & -0.539 & .002 & -0.298 & .031 \\
\hline $\begin{array}{l}\text { Age } \\
\text { Under } 24 \text { years }( \\
24-34 \text { years } \\
35-49 \text { years } \\
\text { 50-64 years } \\
\text { Above } 64 \text { years }\end{array}$ & $\begin{array}{l}-0.519 \\
-0.818 \\
-0.519 \\
-0.238\end{array}$ & $\begin{array}{l}.101 \\
.007 \\
.098 \\
.630\end{array}$ & $\begin{array}{r}-0.013 \\
-0.056 \\
0.021 \\
-1.003\end{array}$ & $\begin{array}{l}.976 \\
.892 \\
.961 \\
.157\end{array}$ & $\begin{array}{l}-0.313 \\
-0.509 \\
-0.810 \\
-0.435\end{array}$ & $\begin{array}{l}.378 \\
.138 \\
.023 \\
.450\end{array}$ \\
\hline $\begin{array}{l}\text { Region } \\
\text { Catalonia (BC) } \\
\text { Madrid } \\
\text { Valencia } \\
\text { Galicia } \\
\text { Basque Country }\end{array}$ & $\begin{array}{l}0.457 \\
0.243 \\
0.191 \\
0.194 \\
\end{array}$ & $\begin{array}{l}.044 \\
.191 \\
.340 \\
.309 \\
\end{array}$ & $\begin{array}{r}-0.420 \\
-0.492 \\
-0.053 \\
0.061 \\
\end{array}$ & $\begin{array}{l}.146 \\
.041 \\
.830 \\
.793 \\
\end{array}$ & $\begin{array}{l}0.261 \\
0.205 \\
0.010 \\
0.135 \\
\end{array}$ & $\begin{array}{l}.280 \\
.334 \\
.962 \\
.503 \\
\end{array}$ \\
\hline Trip-Related Attrib & & & & & & \\
\hline $\begin{array}{l}\text { Type of user } \\
\text { Occasional (BC) } \\
\text { Frequent }\end{array}$ & 0.290 & .073 & -0.020 & .920 & 0.354 & .082 \\
\hline $\begin{array}{l}\text { Type of vehicle } \\
\text { Car (BC) } \\
\text { Van } \\
\text { Truck } \\
\text { Motorcycle } \\
\text { Bus }\end{array}$ & $\begin{array}{r}0.033 \\
0.042 \\
-0.259 \\
1.773\end{array}$ & $\begin{array}{l}.871 \\
.861 \\
.781 \\
.109\end{array}$ & $\begin{array}{r}-0.325 \\
-0.512 \\
0.327 \\
-1.971\end{array}$ & $\begin{array}{l}.206 \\
.102 \\
.729 \\
.398\end{array}$ & $\begin{array}{r}-0.033 \\
0.921 \\
0.557 \\
0.764\end{array}$ & $\begin{array}{l}.874 \\
.001 \\
.635 \\
.375\end{array}$ \\
\hline $\begin{array}{l}\text { Type of trip } \\
\text { Urban trip (BC) } \\
\text { Interurban trip } \\
\text { Long distance }\end{array}$ & $\begin{array}{l}0.378 \\
0.281\end{array}$ & $\begin{array}{l}.020 \\
.138\end{array}$ & $\begin{array}{l}0.222 \\
0.123\end{array}$ & $\begin{array}{l}.287 \\
.626\end{array}$ & $\begin{array}{l}0.334 \\
0.701\end{array}$ & $\begin{array}{l}.046 \\
.001\end{array}$ \\
\hline$\overline{\text { Attitudinal Factors }}$ & & & & & & \\
\hline Quality of the TR & 0.100 & .121 & 0.145 & .079 & 0.087 & .174 \\
\hline $\begin{array}{l}\text { Forced to use the T } \\
\text { Not forced (BC) } \\
\text { Forced }\end{array}$ & 0.010 & .938 & -0.414 & .009 & 0.183 & .176 \\
\hline $\begin{array}{l}\text { Qualitative willing, } \\
\text { Low (BC) } \\
\text { Medium } \\
\text { High }\end{array}$ & $\begin{array}{l}-0.156 \\
-0.070\end{array}$ & $\begin{array}{l}.293 \\
.645\end{array}$ & $\begin{array}{l}-0.516 \\
-0.456\end{array}$ & $\begin{array}{l}.005 \\
.013\end{array}$ & $\begin{array}{r}-0.010 \\
0.068\end{array}$ & $\begin{array}{l}.950 \\
.663\end{array}$ \\
\hline $\begin{array}{l}\text { Perception of the } \mathrm{T} \\
\text { Cheap (BC) } \\
\text { Expensive } \\
\text { Reasonable }\end{array}$ & $\begin{array}{r}-0.184 \\
0.238\end{array}$ & $\begin{array}{l}.784 \\
.727\end{array}$ & $\begin{array}{r}-0.374 \\
0.182\end{array}$ & $\begin{array}{l}.611 \\
.807\end{array}$ & $\begin{array}{l}0.933 \\
1.170\end{array}$ & $\begin{array}{l}.195 \\
.110\end{array}$ \\
\hline $\begin{array}{l}\text { Perception of the ti } \\
\text { Positive (BC) } \\
\text { Negative } \\
\text { Sometimes }\end{array}$ & $\begin{array}{l}-0.784 \\
-0.390\end{array}$ & $\begin{array}{l}.046 \\
.027\end{array}$ & $\begin{array}{l}-0.028 \\
-0.307\end{array}$ & $\begin{array}{l}.953 \\
.188\end{array}$ & $\begin{array}{l}-0.399 \\
-0.227\end{array}$ & $\begin{array}{l}.309 \\
.210\end{array}$ \\
\hline Other Variables & & & & & & \\
\hline $\begin{array}{l}\text { Existing discount } \mathrm{f} \\
\text { No (BC) } \\
\text { Yes }\end{array}$ & 0.117 & .552 & -0.046 & .844 & -0.352 & .079 \\
\hline $\begin{array}{l}\text { Quality of the free } \\
\text { Conventional roa } \\
\text { Highway }\end{array}$ & 0.009 & .967 & 0.121 & .656 & 0.305 & .157 \\
\hline $\begin{array}{l}\text { Intercept } \\
-2 \text { log likelihood } \\
\rho^{2}\end{array}$ & $\begin{array}{r}0.902 \\
1,528.30 \\
.063\end{array}$ & & $\begin{array}{r}-0.367 \\
1,136.25 \\
.083\end{array}$ & & $\begin{array}{r}-1.237 \\
1,493.94 \\
.097\end{array}$ & \\
\hline
\end{tabular}

NotE: $\mathrm{BC}=$ base case; $\mathrm{TR}=$ toll road . 


\section{CONCLUSIONS AND POLICY RECOMMENDATIONS}

This research explored the acceptability of the hypothetical implementation of three highly differentiated road-pricing schemes, for individuals already being charged for the use of roads. Based on individual data from a nationwide survey of road users of the toll network in Spain, three binomial logit models were developed to analyze the relative importance of different explanatory variables related to $(a)$ personal socioeconomic characteristics, such as age, gender, and household income; $(b)$ trip-related attributes, such as usual trips undertaken or type of vehicle; and $(c)$ personal attitudes about toll facilities, such as the perceived effectiveness of toll roads in reducing travel time. The analysis yielded some interesting conclusions.

The first conclusion is that user acceptability of the different proposed strategies - a surcharge to avoid congestion at any time (express toll lanes), time-based (peak versus off-peak) pricing, and a flat fee charge-is influenced by various factors, so a common trend cannot be determined. The research provided evidence that users' perceptions and conditionings vary noticeably with the type of charging scheme proposed. For instance, for the case of express toll lanes, the perceived effectiveness of the toll facility in contributing to saving travel time prevails over other individual variables. However, feeling forced to use the toll road plays a significant role in explaining levels of acceptability in the case of time-based (peak versus off-peak) pricing schemes. Finally, the type of vehicle driven and the type of trip usually made were the most important factors explaining acceptability of a flat fee scheme.

The second conclusion is that support for alternative pricing options does not seem to be related to income. By contrast, attitudinal factors were found to have a greater impact on acceptability compared with personal socioeconomic characteristics. These findings are largely consistent with the literature. However, in certain cases, users' perceptions may be influenced by individual characteristics such as gender and region of residence. In any case, the influence of socioeconomic variables on users' perceptions - especially those that have not generally led to conclusive and coincident results, such as age, gender, and income-needs to be explored more deeply.

The third conclusion is that real users of a toll network seem to have different perceptions of the three alternative pricing schemes. The survey respondents related a time-based (peak versus off-peak) charge to a higher burden to be borne, and saw a flat fee charge as a potential way to save money. As users feel obliged to use the toll road, they are less prone to accept a time-based (peak versus off-peak) scheme, but more favorable to a flat fee system. This result means that respondents who feel that they are captive users - those who in practice do not have an alternative option for their daily travel-accept or reject a scheme depending on its ability to achieve substantial cost savings. In this sense, the outcomes of this research are useful for crafting the schemes proposed or the messages directed to specific groups of opponents and even proponents, as well as for predicting the future behavior of users.

Based on the findings of this study, some policy recommendations might be addressed to decision makers:

- The first important aspect to be considered for user acceptability is the type of road-pricing strategy to be implemented. Hence, reactions to price changes are expected to be much stronger and more negative for schemes associated with greater variability (time-, distance-, or delay-based charging mechanisms) than for fixed charge systems. Therefore, policy makers should pursue options that are technically feasible, transparent, and easy to understand.

- The premise that the acceptability of each scheme is influenced by factors of a different nature is a necessary precondition for an acceptable pricing scheme. A proper understanding of these differences can help planners to enhance acceptability for each specific type of pricing mechanism.

- Transport planners and decision makers should be aware of the differences in public support for road-pricing schemes before and after their implementation. In the case of a pricing scheme that is to be implemented, providing the public with detailed information about its objectives and potential impacts is essential to guarantee the success of road pricing, given that individuals do not have past experiences on which to base their opinion.

- The fact that attitudinal factors explain acceptability better than socioeconomic variables do constitutes another important factor that provides useful insight for transportation professionals. Understanding attitudes, as well as the reasons behind them, seems to be a crucial aspect for predicting social behavior and reactions toward new transport pricing schemes.

From the results presented in this paper, some aspects can be pointed out for further research. Because the analysis only considered work trips, future studies should attempt to extend the analysis by exploring other trip purposes. In addition, potential differences in acceptability across groups of respondents, that is, users and nonusers of toll roads, should be analyzed in greater detail by adopting more suitable econometric specifications, such as multilevel models. Finally, additional research should delve more deeply into how people react to different levels of charges within the same pricing scheme. For example, this paper raised the general issue of different pricing systems but did not examine variations in the acceptability of different fee scenarios.

\section{REFERENCES}

1. Kockelman, K. M., K. Podgorski, M. Bina, and S. Gadda. Public Perceptions of Pricing Existing Roads and Other Transportation Policies: The Texas Perspective. Journal of the Transportation Research Forum, Vol. 48, No. 3, 2012, pp. 19-38. http://dx.doi.org/10.5399/osu /jtrf.48.3.2316.

2. Link, H., and J. Polak. How Acceptable Are Transport Pricing Measures? Empirical Studies in Nine European Countries. Presented at 29th European Transport Conference, Cambridge, 2001.

3. Jaensirisak, S., M. Wardman, and A. May. Explaining Variations in Public Acceptability of Road Pricing Schemes. Journal of Transport Economics and Policy, Vol. 39, No. 2, 2005, pp. 127-153.

4. May, A.D., A. Koh, D. Blackledge, and M. Fioretto. Overcoming the Barriers to Implementing Urban Road User Charging Schemes. European Transport Research Review, Vol. 2, No. 1, 2010, pp. 53-68. http:// dx.doi.org/10.1007/s12544-010-0026-1.

5. Gomez, J., A. Papanikolaou, and J. M. Vassallo. Users' Perceptions and Willingness to Pay in Interurban Toll Roads: Identifying Differences Across Regions from a Nationwide Survey in Spain. Transportation, 2015, pp. 1-26.

6. Odeck, J., and S. Bråthen. Toll Financing in Norway: The Success, the Failures and Perspectives for the Future. Transport Policy, Vol. 9, No. 3, 2002, pp. 253-260. http://dx.doi.org/10.1016/S0967-070X(02)00030-6.

7. Teubel, U. The Welfare Effects and Distributional Impacts of Road User Charges on Commuters: An Empirical Analysis of Dresden. International Journal of Transport Economics, Vol. 27, No. 2, 2000, pp. 231-255.

8. Bureau, B., and M. Glachant. Distributional Effects of Road Pricing: Assessment of Nine Scenarios for Paris. Transportation Research Part A, Policy and Practice, Vol. 42, No. 7, 2008, pp. 994-1007. http://dx.doi.org /10.1016/j.tra.2008.02.001. 
9. Jakobsson, C., S. Fujii, and T. Gärling. Determinants of Private Car Users' Acceptance of Road Pricing. Transport Policy, Vol. 7, No. 2, 2000 pp. 153-158. http://dx.doi.org/10.1016/S0967-070X(00)00005-6.

10. Noordegraaf, D. V., J.A. Annema, and B. van Wee. Policy Implementation Lessons from Six Road Pricing Cases. Transportation Research Part A, Policy and Practice, Vol. 59, 2014, pp. 172-191. http://dx.doi.org /10.1016/j.tra.2013.11.003.

11. Schade, J., and M. Baum. Reactance or Acceptance? Reactions Towards the Introduction of Road Pricing. Transportation Research Part A, Policy and Practice, Vol. 41, No. 1, 2007, pp. 41-48. http://dx.doi.org /10.1016/j.tra.2006.05.008.

12. Grisolía, J.M., F. López, and J.D.D. Ortúzar. Increasing the Acceptability of a Congestion Charging Scheme. Transport Policy, Vol. 39, April 2015, pp. 37-47. http://dx.doi.org/10.1016/j.tranpol.2015.01.003.

13. Li, Z., and D.A. Hensher. Congestion Charging and Car Use: A Review of Stated Preference and Opinion Studies and Market Monitoring Evidence. Transport Policy, Vol. 20, 2012, pp. 47-61. http://dx.doi.org /10.1016/j.tranpol.2011.12.004.

14. Fürst, E.W.M., and M. Dieplinger. The Acceptability of Road Pricing in Vienna: The Preference Patterns of Car Drivers. Transportation, Vol. 41, No. 4, 2014, pp. 765-784. http://dx.doi.org/10.1007/s11116-013-9485-2.

15. Gaunt, M., T. Rye, and S. Allen. Public Acceptability of Road User Charging: The Case of Edinburgh and the 2005 Referendum. Transport Reviews, Vol. 27, No. 1, 2007, pp. 85-102. http://dx.doi.org/10.1080 /01441640600831299.

16. Harsman, B., S. Padam, and B. Wijkmark. Ways and Means to Increase the Acceptance of Urban Road Pricing. PRIMA, European Commission, Brussels, 2000.

17. Owen, R., A. Sweeting, S. Clegg, C. Musselwhite, and G. Lyons. Public Acceptability of Road Pricing. Technical Report, Department for Transport, London, 2008. http://eprints.uwe.ac.uk/10351.

18. Schade, J., and B. Schlag. Acceptability of Urban Transport Pricing. Research Report No. 72, Government Institute for Economic Research Finland, Helsinki, 2000.

19. Dill, J., and A. Weinstein. How to Pay for Transportation? A Survey of Public Preferences in California. Transport Policy, Vol. 14, No. 4, 2007 pp. 346-356. http://dx.doi.org/10.1016/j.tranpol.2007.04.001.

20. Zmud, J., and C. Arce. Compilation of Public Opinion Data on Tolls and Road Pricing. NCHRP, Washington, D.C., 2008. http://dx.doi.org $/ 10.17226 / 14151$

21. Vrtic, M., N. Schuessler, A. Erath, and K.W. Axhausen. Design Elements of Road Pricing Schemes and Their Acceptability. Presented at 86th Annual Meeting of the Transportation Research Board, Washington, D.C., 2007, pp. 1-19.

22. Schaller, B. Battling Traffic: What New Yorkers Think About Road Pricing. Manhattan Institute for Policy Research, New York, 2006. http://www.ecoplan.ch/download/e73_sb_en.pdf. Accessed May 5, 2016.

23. Rienstra, S.A., P. Rietveld, and E.T. Verhoef. The Social Support for Policy Measures in Passenger Transport. Transportation Research Part D: Transport and Environment, Vol. 4, No. 3, 1999, pp. 181-200. http://dx.doi.org/10.1016/S1361-9209(99)00005-X.

24. Golob, T. F. Joint Models of Attitudes and Behavior in Evaluation of the San Diego I-15 Congestion Pricing Project. Transportation Research
Part A: Policy and Practice, Vol. 35, No. 6, 2001, pp. 495-514. http:// dx.doi.org/10.1016/S0965-8564(00)00004-5.

25. Braunholtz, S., R. Cumming, and M. Scotland. Evaluation of Edinburgh Residents' Attitudes to the Proposed Road User Charging Scheme. Transport Research Series, No. 223, Scottish Executive Social Research, 2006.

26. Gehlert, T., C. Kramer, O.A. Nielsen, and B. Schlag. Socioeconomic Differences in Public Acceptability and Car Use Adaptation Towards Urban Road Pricing. Transport Policy, Vol. 18, No. 5, 2011, pp. 685-694. http://dx.doi.org/10.1016/j.tranpol.2011.01.003.

27. PATS. Final Report Pricing Acceptability in the Transport Sector, Concerted Action on Transport Pricing Research Integration. European Commission, Brussels, 2001.

28. Dieplinger, M., and E. Fürst. The Acceptability of Road Pricing: Evidence from Two Studies in Vienna and Four Other European Cities. Transport Policy, Vol. 36, 2014, pp. 10-18. http://dx.doi.org/10.1016 /j.tranpol.2014.06.012.

29. Hao, X., X. Sun, and J. Lu. The Study of Differences in Public Acceptability Towards Urban Road Pricing. Procedia: Social and Behavioral Sciences, Vol. 96, 2013, pp. 433-441. http://dx.doi.org/10.1016/j.sbspro 2013.08.051.

30. Schade, J. Public and Political Acceptability as Criteria for Implementation Paths: Urban and Interurban Road. Presented at MC-ICAM Conference. Helsinki, Finland, 2002.

31. Matas, A., and J. Raymond. Demand Elasticity on Tolled Motorways. Journal of Transportation and Statistics, Vol. 6, No. 2, 2003, pp. 91-109.

32. Ministerio de Fomento. Anuario estadístico 2013. Centro de Publicaciones, Secretaría General Técnica, Madrid, 2014.

33. Ben-Akiva, M. Discrete Choice Analysis Theory and Application to Travel Demand. MIT Press, Cambridge, Mass., 1985.

34. Louviere, J. J., T. N. Flynn, and R. T. Carson. Discrete Choice Experiments Are Not Conjoint Analysis. Journal of Choice Modelling, Vol. 3, No. 3, 2010, pp. 57-72. http://dx.doi.org/10.1016/S1755-5345(13)70014-9.

35. Peng, C. Y., and T.S. So. Logistic Regression Analysis and Reporting: A Primer. Understanding Statistics, Vol. 1, No. 1, 2002, pp. 31-70. http://dx.doi.org/10.1207/S15328031US0101_04.

36. Ortúzar, J.D.D., and L.G. Willumsen. Modelling Transport, 4th ed. John Wiley \& Sons, Ltd., Chichester, U.K., 2011. http://dx.doi.org /10.1002/9781119993308.

37. Gomez, J., A. Papanikolaou, and J. M. Vassallo. Measuring Regional Differences in Users' Perceptions Towards Interurban Toll Roads. Journal of Transport Geography, Vol. 54, 2016, pp. 22-33. http://dx.doi.org /10.1016/j.jtrangeo.2016.05.001.

38. Bonsall, P. W., and H.-J. Cho. Travellers' Response to Uncertainty: The Particular Case of Drivers' Response to Imprecisely Known Tolls and Charges. Transportation Planning Methods. Proceedings of Seminar F, European Transport Conference. Cambridge, United Kingdom, 1999.

39. Hensher, D. A., and M. Bradley. Using Stated Response Choice Data to Enrich Revealed Preference Discrete Choice Models. Marketing Letters, Vol. 4, No. 2, 1993, pp. 139-151. http://dx.doi.org/10.1007/BF00994072. 